\title{
Francisco Javier Fernández Conde, José María Mínguez y ERmelindo Portela, EL ReINO DE HisPaNIA (SIGLOS VIII-XII). TEORÍA Y PRÁCTICAS DEL PODER, MADRID, EdICIONES AKAL, 2019, 427 PÁGS. ISBN: 978-84-460-4743-8.
}

\author{
Sonia Vital Fernández \\ Doctora en Historia por la Universidad de Salamanca
}

El concepto Hispania que aparece en los textos cronísticos y diplomáticos de los siglos VIII al XII relacionado con los reyes de Oviedo y de León es la base para el análisis de la ideología regia, pero también del ejercicio del poder-Teoría y prácticas del poder-que se realiza en esta obra. Un análisis que pone el foco en el poder político como constructor de relaciones sociales de poder. Porque el libro es, sobre todo, una historia social del poder; una historia política examinada desde abajo, como expresan los autores. Se trata de un enfoque que tiene en cuenta, especialmente y más allá del poder ejercido por los reyes, el practicado por los poderes establecidos en cada uno de los territorios del reino y que, como se demuestra a lo largo de la obra, resulta muy valioso para conocer el tablero político del reino y el juego de poder que se proyecta en él. De esta manera, el lector va a encontrar en El reino de Hispania una profunda reflexión acerca de los problemas que plantea la historia política y social entre la desaparición de la monarquía visigoda y la implantación de las estructuras políticas plenamente feudales. Cuestiones de gran complejidad que son abordadas con celo y desde el enorme bagaje de conocimiento acumulado durante años por los tres catedráticos, autores de este libro, que han colaborado de forma conjunta desde el año 1994 en múltiples proyectos de investigación.

La primera parte del libro, firmada por Francisco Javier Fernández Conde, se ocupa de la ideología teocrática del poder político de los reyes cristianos desde el período astur hasta la reina Urraca I. En ella, el autor demuestra que la sacralización de los reyes fue clave para su legitimación y para la construcción teórica del poder que ejercieron. Lo hace, en primer lugar, retrotrayéndose a sus orígenes tardoantiguos, cuando se asentó el agustinismo político y se implantó la concepción sagrada del poder político de los reyes, para, después, rastrear los ecos de esta teoría política en los textos cronísticos, pero, sobre todo, en las intitulaciones, protocolos y escatocolos de una enorme base documental integrada por un total de 5706 piezas, entre diplomas regios y documentos 
privados. Semejante arsenal de datos permite al autor hacer un recorrido cronológico que brinda interesantes conclusiones acerca de la construcción del poder regio y que revela, también, la participación política de los otros poderes del reino.

De este modo, Fernández Conde ilustra cómo, progresivamente, junto a la figura del princeps o rex, investido bajo la fórmula de rex Dei gratia, van apareciendo otros actores políticos: primero, su cónyuge, con el título de reina y con expresiones que apuntan a un cierto correinado; después, de forma cada vez más destacada, a continuación del rey y de la familia real, los obispos validantes, lo que se explica por la notoria posición que estos van adquiriendo en las tareas de gobierno, especialmente en los lugares más distantes de Oviedo. Por el contrario, las referencias a condes son más escasas en los primeros tiempos, a pesar de su no menos relevante actuación en tareas de gobierno, conquista y repoblación, lo que, para el autor, sugiere que el aparato administrativo estaba aún poco consolidado y que en la reorganización del territorio seguirían todavía presentes las figuras ancestrales de poderes locales. Sin embargo, el traslado de la sede regia a León supone cambios importantes: aumenta la presencia de condes en la documentación, sobre todo castellanos, por el evidente protagonismo que Castilla empezará a jugar desde ese momento en la evolución del reino y, además, los diplomas insisten en dejar constancia del linaje de cada soberano, a menudo, con la intitulación de reyes de Oviedo; lo que contribuía a reafirmar la legitimación de los reyes en un momento en que la tradición hereditaria de la monarquía todavía no se había consolidado.

No podía faltar, en el análisis de Fernández Conde, una reflexión sobre el concepto de Imperio leonés que tiene su origen en esta época y que triunfa con la presencia de la dinastía navarra en León, cuando adquiere un significado distinto. En efecto, el estudio de la documentación que lleva a cabo el autor confirma lo que ya han apuntado otros autores sobre este concepto: que el término imperator no era más que un sinónimo de rex o princeps que habría servido para enfatizar la autoridad regia en tiempos de Alfonso III, pero que en ningún caso sería el reflejo de una autoridad sobre Hispania. Realidad que cambia en época de Alfonso VI cuando el título sirvió para enfatizar la extensión de la autoridad del rey sobre una importante parte de la Península, mientras que su predominio económico y político sobre varias taifas le aseguraba, también, una autoridad sobre toda Hispania. Esta idea es la que tratarán de reivindicar sus herederos, aunque el título imperial adquiere un matiz distinto con cada uno de ellos. Es interesante la constatación de que, con la implantación de la dinastía navarra en León, no se detectan novedades respecto a la concepción del poder, pero sí se intensifica el interés por subrayar la legitimidad de la nueva dinastía. En esa legitimidad juega un papel fundamental la reina Sancha que es quien transmite a su esposo Fernando los derechos dinásticos del reino de León. Habrá que esperar, sin embargo, al reinado de su nieta, Urraca I, para que una mujer se corone reina en León como titular. Y es en ese momento cuando la documentación insiste en la legitimidad de la reina sobre los territorios que había gobernado su padre Alfonso VI. No es casual esta insistencia teniendo en cuenta que la condición de Urraca de primera reina-mujer al frente del reino necesitaría ser respaldada en la legitimidad dinástica. Me parece este un hecho de especial importancia 
en la construcción del poder regio que, quizás, en un futuro, merecería ser tratado con mayor amplitud.

Este largo y detallado recorrido teórico confirma que la concepción política de los reyes de Oviedo y León cuenta con una tradición que hunde sus raíces en época tardoantigua, que es heredada e implantada por los reyes astures y que se va acomodando, durante todo el período, a las dificultades políticas que cada momento histórico plantea a los reyes. Llegados a este punto, la teoría del poder da paso a su ejercicio práctico. A su análisis se dedican la segunda y tercera partes del libro, donde se ponen en evidencia las distintas prácticas de poder, resultado de la diversidad social y territorial del reino de Hispania.

La segunda parte, escrita por la pluma de José María Mínguez, se centra en los espacios fronterizos del reino astur, y luego del reino de León, con los otros poderes cristianos en su parte oriental. Destaca, en este análisis, el territorio al este de los ríos Cea y Pisuerga: un espacio con trazas de la organización social y política de época romana y visigoda, sujeto a cambiantes circunstancias sociales y políticas, y a influencias astures, leonesas, castellanas y navarras. Este territorio tiene, para Mínguez, una relevancia histórica por su implicación en los procesos políticos, sociales y económicos en el período alto y plenomedieval; y el autor lo define como fronterizo porque su valor estratégico se pone de relieve en función de las distintas separaciones y unificaciones de León y Castilla, precisamente, por las profundas diferencias de la sociedad que se sitúa en esas tierras.

Pero, para tratar de comprender cómo se organizaron esos territorios y cómo fue su integración en el reino, el autor retrocede a la primera época astur, cuyo interés reivindica para comprender la evolución posterior. Y lo hace con una reveladora reflexión: en su opinión, la sociedad de esa época era políticamente inmadura y carecía de un sistema sucesorio institucionalizado por el carácter efímero de los caudillos y de su gobierno inestable y poco centralizador. Esto último lleva a Mínguez a afirmar, en contra de lo que ha apuntado la historiografía tradicional, que hasta Alfonso II no puede hablarse de rey, sino de un caudillo - que accedía a la jefatura militar a partir de un pacto con sus socios-. Y, sin embargo, fueron estos primeros caudillos los que organizaron el amplio territorio astur, apoyados en los jefes locales existentes, y su evolución social, política y militar hizo posible la configuración de la monarquía. Configuración que Mínguez detecta solo a partir de Alfonso II, cuando se concreta un afianzamiento del poder del linaje regio, pero también, y lo que es más importante, una justificación teórica del poder, apoyada por la elite cultural y basada en la tradición visigoda, que permitirá el ensalzamiento de la función y figura del rey.

Una vez que la sociedad astur ha alcanzado esta cohesión interna podrá enfrentarse al islam y expandirse. A partir de ahí, el autor analiza la expansión sobre los territorios orientales, centrándose especialmente en los cántabro-orientales, vizcaínos y en el alto Ebro -la Castella o Castella uetula-, que reviste de una gran complejidad: son espacios donde la tradición romano-visigoda apenas ha penetrado y donde las unidades sociales se organizan en torno a un jefe local que será clave para el control y organización 
del territorio, así como para su integración en el reino astur, a veces de forma muy precaria. En esa integración será también fundamental la acción desplegada sobre el territorio y su sociedad por parte de los nuevos centros religiosos: los monasterios que se constituyen como articuladores de la economía, sociedad y administración, y como aplicadores del poder político.

La singularidad de la frontera oriental del reino dificulta, asimismo, el proceso repoblador que los reyes encomendaron a los condes, antiguos jefes locales. Estos empezarán a aparecer de forma habitual dominando y organizando la frontera oriental del reino y liderando campañas de conquista y de repoblación, pero también ideando las líneas de defensa frente a los andalusíes con gran autonomía respecto al reino. En la práctica, estos condes estaban organizando políticamente los territorios de forma autónoma, lo que pronto se tradujo en rebeliones contra los reyes astures. Y en este complejo contexto ha de situarse la formación del condado de Castilla que mantiene con León una relación de subordinación política formal, pero también una fuerte tendencia a la autonomía, aunque, como demuestra Mínguez, nunca se intentó suplantar la soberanía de los reyes astur-leoneses.

Mínguez dedica la última parte de su estudio a analizar la intervención de Sancho Garcés III el Mayor en los territorios al oeste de las fronteras originarias de Pamplona y al posterior fortalecimiento de León y de Castilla. Esta última emergerá con fuerza para alcanzar, a finales del siglo XII, una plena hegemonía peninsular y reafirmar el papel político prioritario que asumirá en adelante. De esta manera, el autor cierra su discurso planteando las bases históricas y las tendencias que abrirán una nueva etapa en la Edad Media peninsular.

La última parte del libro, la tercera, está dedicada al estudio del área occidental del reino: la Gallaecia, cuyas características son sensiblemente distintas a las estudiadas por Mínguez en la parte oriental. Aquí su autor, Ermelindo Portela, hace hincapié en la continuidad de una tradición antigua que se remonta a época romana, al reino de los suevos, que pervive en época visigoda y que se mantiene con la desaparición del reino visigodo. En efecto, constata, el autor, que la escasa presencia de los musulmanes en el territorio al norte del Duero en el siglo VIII no la habría alterado. De modo que la estructura organizativa y social de ese espacio se mantiene bajo el patrocinio de obispos y aristócratas laicos que actúan como poderes políticos en el ámbito local; lo que le lleva a afirmar que la integración de estos poderes en el reino astur y astur-leonés no puede explicarse en términos de reconquista y repoblación porque este territorio ni había sido conquistado, ni se había convertido en un desierto. La actividad de las villae de los documentos es sumamente reveladora en este sentido: se trata de redes de poblamiento donde se mantiene una explotación agraria y una organización de época visigótica y donde actúan poderes locales que son los que pactan la aceptación del dominio de los nuevos gobernadores hasta mediados del siglo VIII, cuando los árabes y beréberes, imbuidos en problemas internos, se desplazan al sur de la meseta central. Y esos poderes, determinantes para la continuidad de la tradición social, lo serán también para la lenta y compleja integración en el reino astur. 
En cuanto a esta segunda cuestión, el autor defiende que entre los reyes de Oviedo y los poderosos de Gallaecia también se había producido un pacto que habría facilitado el ejercicio ordenado del poder de los jefes locales, algo fundamental para la lenta incorporación de este territorio al reino astur. Además, este pacto habría proporcionado a los jefes locales un ascenso social frente a otros poderosos que los van a reconocer gracias al ejercicio de poderes públicos delegados. El conde Aloito o los obispos Kindulfo y Teodomiro de Iria son ejemplos destacados de esta casuística. Consigue constatar, Portela, que, en este proceso de integración del territorio en el reino astur, es el orden político lo que se restablece.

A partir de este momento, el hilo conductor del discurso del autor se mantiene en el apoyo de los reyes en los poderes locales de la Gallaecia, cuyo papel, una vez más, fue decisivo en la construcción política, ahora en un contexto feudal. Es del mayor interés el análisis dedicado al reino de Galicia gobernado por García II, del que Portela es buen conocedor. Pero no menos importante para la evolución política de este territorio y del conjunto del reino es la época de Alfonso VI. El autor demuestra que, en la separación de Galicia de Portugal, que terminará por segregarse del reino de Hispania dando lugar a un reino distinto, tienen un peso importante los movimientos de los poderes locales -obispos, aristocracia laica y burgueses-, cuyos intereses en el juego político fluctuaban, en ese momento, a ambos lados de la frontera del Miño. La figura del obispo y arzobispo Diego Gelmírez, un poderoso local con gran proyección en el reino de Hispania, es, sin duda, la más representativa de este proceso que pone fin al estudio de Portela.

En conjunto, este largo itinerario por el reino de Hispania constituye una profunda y valiosa aportación sobre las implicaciones políticas y sociales del ejercicio del poder. Cuestiones que los autores han sacado a la luz gracias a un enfoque político en el que prima la actuación de los poderes enraizados en los distintos territorios del reino, lo que les ha permitido explicar los procesos de integración y de articulación de los territorios del noroeste peninsular al reino de Hispania, incorporando, asimismo, las aportaciones de la más reciente historiografía sobre esta temática. Sin duda, este libro está llamado a ser un referente para los estudios sobre la Alta y Plena Edad Media peninsular. 